to have rewarded our attempts to graduate leakage in accordance with the needs of the case. I readily believe that the dangerous conjunctival blebs with hypotony, which betoken excessive leakage, may have been rare in Colonel Elliot's hands. Yet he has insisted both at the last Oxford Congress and again now, that some risk of infection must be accepted as inevitable with all the modern successful glaucoma operations. I would certainly agree with this opinion if we had no resource but iris-free fistulization. It seems fairly well established that in many of the severer chronic glaucomas the flow of aqueous needed for full relief of tension is so great that it cannot be obtained by iris-free drainage without risk, sometimes perhaps considerable risk.

In conclusion, it is well to bear in mind that only one of the two chief defects of drainage by fistulization has been discussed above. The value of this form of drainage must depend very largely on the question of the permanence of relief of tension provided by the smaller fistulae, yet to be decided.

I hope to bring up the question of the treatment of glaucoma by iris-prolapse at the Ophthalmological Society's Congress in May.

Yours truly,

H. HERBERT, Lt.-Colonel, I.M.S.

\title{
A SCHOOL OF OPHTHALMOLOGY FOR LONDON
}

\section{To the Editor of The British Journal of Ophthalmology}

SIR,-I must confess to a feeling of disappointment that the admirable suggestion made by Mr. M. S. Mayou in the February number of the Journal has not met with the open endorsement of readers. He practically proposes to amalgamate and to co-ordinate "The principal leading schools attached to the ophthalmic hospitals in London" for teaching purposes. I write in cordial agreement with Mr. Mayou. When I first came to London, tolerably acquainted with clinical and operative eye work, I hastened to attach myself to one of the ophthalmic hospitals, not one of the least well reputed. The teaching based on actual clinical material could not well be beaten, but when I began to look about for tuition in pathology I found that although a gentleman bore the title of "pathologist" to the institution, I had never seen him, and though well acquainted with the hospital premises, failed utterly to locate his habitat. As a result I was compelled to seek pathological instruction elsewhere. Again, as to optics, no attempt was made at the hospital in question to instruct students in what I knew to be from my text books an important subject. Accordingly, I was driven to attend 
the class held, presumably for opticians, at The City and Guilds Institute by the late Professor Sylvanus Thompson. I was well rewarded. A properly equipped ophthalmic school should obviously lay itself out to teach, not only ophthalmology, but the ancillary sciences as well.

Later, when settled in practice, and having visited many ophthalmic clinics, both upon the Continent and in America, it occurred to me that the weak point of the present system in London might be closely connected with the fact that the school was always an adjunct to the hospital and that better results might perhaps be obtained by reversing the relationship. I imagined an institution, a school of ophthalmic technology, provided with teachers, skilled in all the auxiliary branches of ophthalmology, with optical and bacteriological laboratories and with a small outpatient department and a few beds, enough to give means for adequate clinical instruction and no more. Such a plan would not be expensive to create, and the fees charged afterwards should make it self-supporting. The qualification of a teacher should be one, namely, that he knew how to teach.

WELBECK STREET, W, Yours, etc.,

March 9.

SYDNEY STEPHENSON.

\section{AN INTERNATIONAL CONGRESS OF OPHTHALMOLOGY}

To the Editor, The British Journal of Ophthalmology.

DEAR SIR,-Owing to a misconception on the part of some as to the exact character of An International Congress of Ophthalmology, which is to be held in Washington, D.C., April 25-28, 1922, I am instructed by the General Committee to prepare the following notice and to request its early publication in the Journal :

First, the proposed Congress is designated as An International Congress of Ophthalmology, which will be held under the auspices of the American Ophthalmological Society, the Section, on Ophthalmology of the American Medical Association and the American Academy of Ophthalmology and Oto-Laryngology. It is an independent Congress and is in no way affiliated with, or a continuation of, the regularly constituted International Congress of Ophthalmology which has convened at regular intervals in the past, the last session of which was to have taken place in St. Petersburg in 1914 at the outbreak of the war.

Second, because of unavoidable complications in the arrangement of the proper and comfortable accommodations for the delegates of 